\title{
Recorregut de recerca geològica i mineralògica per la comarca del Pallars Sobirà: des de Caregue alCcoll de Portella, al Estanys de Mairena, al Coll d'Eixol i a Superespot
}

Josep Maria Mata-Perelló Joaquim Sanz Balagué

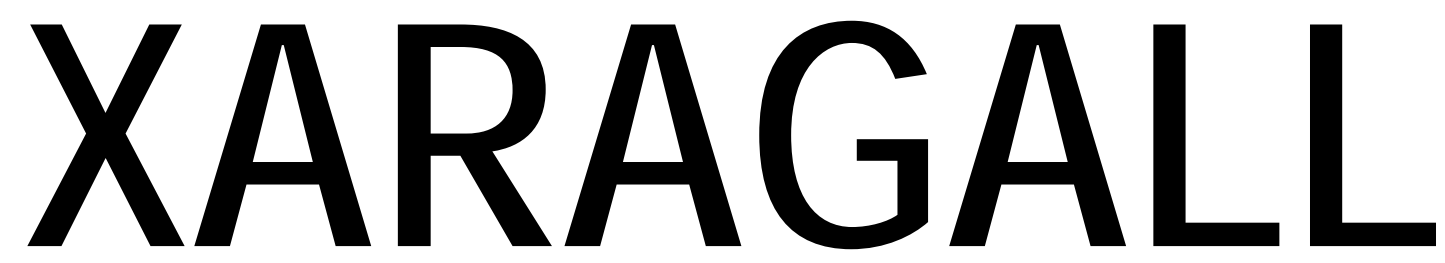

\section{REVISTA DE CIÈNCIES DE LA CATALUNYA CENTRAL}

\section{n. 11}

NOVEMBRE 2014 


\title{
RECORREGUT DE RECERCA GEOLÒGICA I MINERALÒGICA PER LA COMARCA DEL PALLARS SOBIRÀ: DES DE CAREGUE AL COLL DE PORTELLA, AL ESTANYS DE MAIRENA, AL COLL D’EIXOL I A SUPERESPOT
}

\author{
Josep Maria Mata-Perelló \\ Museu de geologia Valentí Masachs, Escola Politècnica Superior d'Enginyeria de Manresa \\ (EPSEM), Universitat Politècnica de Catalunya · BarcelonaTech (UPC), 08272 Manresa, Spain
}

\section{Joaquim Sanz Balagué}

Departament d'Enginyeria Minera i Recursos Naturals (EMRN), Escola Politècnica Superior d'Enginyeria de Manresa (EPSEM), Universitat Politècnica de Catalunya . BarcelonaTech (UPC), 08272 Manresa, Spain

Paraules clau: Sistema Pirinenc, Zona Axial Pirinenca, Materials paleozoics, Patrimoni miner

\section{Resum}

Itinerari realitzat el 26 d'octubre de 2013. En aquesta ocasió, la totalitat del recorregut de l'itinerari discorrerà íntegrament pel Sistema Pirinenc. Això si, discorrerà sempre el seu recorregut per la Zona Axial Pirinenca (en concret per la denominada Unitat dels Apilaments de la Zona Axial).

Així, tots els materials que anirem trobant en aquest recorregut seran paleozoics, fonamentalment de l'Ordovicià. Tot i això, molt sovint aquests materials els trobarem recoberts per sediments del Pleistocè i de l'Holocè, que molt sovint corresponen als sediments detrítics d'origen glacial: és a dir a les morrenes. També corresponen als sediments fluvials de la Noguera Pallaresa i dels seus diferents afluents.

Per altra banda, el recorregut de l'itinerari discorrerà íntegrament per una sola comarca, concretament per la del Pallars Sobirà, de la Regió de Tremp (o de Tremp-Seu d'Urgell). Al mateix temps, part del recorregut transitarà pel Parc Nacional d'Aigües Tortes, especialment pels voltants del Mairena i de Superespot. 


\section{Objectius fonamentals}

Es centraran en els aspectes geològics, geomorfològics i mineralògics que apuntarem a continuació:

1. Observació de l'estructura del sector corresponent als Apilaments Antiformes de la Zona Axial Pirinenca, per entre la qual discorrerà la totalitat del recorregut de l’itinerari.

2. Observació dels materials paleozoics de la denominada Unitat dels Apilaments de la Zona Axial Pirinenca. Aquests materials pertanyen, segons als llocs al Cambro-Ordovicià, Ordovicià, Silurià i Devonià. i a l'Ordovicià. Tanmateix, trobarem afloraments de roques granítiques, les quals pertanyen al Carbonífer i al Pèrmic, formades durant l'Orogènia Hercínica.

3. Observació dels diferents indrets relacionats amb el Patrimoni Geològic, que anirem trobant al llarg del present itinerari. En concret, cal fer esment del relacionats amb el Patrimoni Geomorfològic, relacionat amb la morfologia glacial.

4. Observació de les mineralitzacions que trobem al llarg del recorregut de l'itinerari, com és el cas de les següents, com les mineralitzacions associades a skarn, que trobarem prop dels estanys de Mairena i de Superespot, amb la presencia d’EPIDOTA i de TREMOLITA (amiant).

5. Observació de les antigues explotacions mineres, com la situada prop dels Estanys de Mairena.

6. Observació, si śescau del Patrimoni Geològic i Miner, que es vagi trobant al llarg del recorregut de l'itinerari.

\section{Antecedents}

Pel que fa al recorregut d'aquest itinerari, no coneixem cap antecedent pel que fa a total recorregut. Així, es podria considerar com una primícia. Tot i així, hi ha un itinerari entre Espot i els Llacs de Mairena, al Ilibre de Martínez et altri 2013. També farem esment d'uns itineraris propers nostres: Mata-Perelló (2013a i b),

Pel que fa a les mineralitzacions que veurem en aquest itinerari, cal dir que també ja estat prèviament descrites per nosaltres en Mata-Perelló (1991). Així, com Mata-Perelló i Sanz Balagué (1993).

I pel que fa a l'estructura geològica, ens remetem al treball de Riba et altri (1976), i al de Guimerà et altri (1992). En ambdós, es fa referència a l'estructura geològica dels Països Catalans. Per d’altra banda, cal fer especial menció del recent treball de Martínez et altri 2013.

Finalment, cal dir que tots aquests treballs, es trobaran relacionats, per estricte ordre alfabètic, dintre de l'apartat dedicat a les REFERÈNCIES BIBLIOGRÀFIQUES, al qual es remetem, pel que s'escaigui. 


\section{Recorregut de l'itinerari}

El recorregut del present itinerari s'iniciarà per les immediacions de la població de Caregue. Des d'aquesta població, caldrà agafar una pista forestal en irregular estat de conservació, per la qual cosa ens caldrà demanar la suficient informació.

Per aquesta pista, arribarem en uns $8 \mathrm{Km}$ al Coll de la Portella. A partir d'aquest indret, ens caldrà seguir cap al Sud, amb la intenció d'arribar al Pas de Mairena, per on seguirem a peu fins als Estanys de Mairena.

De fet, el recorregut de l'itinerari no l'iniciarem fins arribar al Pas de Mairena.

Després de retornar a la pista, convindrà continuar cap al Nord, per tal d'arribar de nou al Coll de la Portella, des d'on anirem després cap al Coll de la Creu d'Eixol. Finalment ens aproparem a Superespot, per tal de fer les darreres.

\section{Advertiments previs}

Com en altres recorreguts de RECERCA GEOLÒGICA I MINERALÒGICA... si es disposa del temps suficient, poden efectuar-se passant per totes les parades i filloles. En cas contrari, recomanem prescindir de les anomenades PARADES - CONDICIONALS.

En aquest itinerari, cal tenir força cura del coneixement sobre l'estat de les pistes de muntanya. Així, en aquest cas hi haurà un recorregut per una llarga pista forestal, que uneix Llessui amb Espot, de la qual no en tenim gaire coneixement sobre el seu estat de conservació. Així, ens caldrà buscar la màxima informació possible i anar amb la màxima cura en tot el recorregut.

Per altra banda, i com de costum, recomanem tenir el màxim respecte per la natura, tant al llarg d'aquest recorregut, com en qualsevol moment, al marge d'ell.

\section{Descripció de l'itinerari}

En aquest recorregut hem situat, com ja és habitual en tots els itineraris, una sèrie d'ESTACIONS o de PARADES, que anirem veient a continuació. En cada cas, els hi donarem una denominació que podrà correspondre a algun paratge proper. També indicarem el terme municipal i la comarca on es troba.

Per altra banda, en cadascuna de les parades, indicarem entre parèntesi el número del "Mapa Topográfico" (de I'Instituto Grográfico y Catastral de España), a escala 1:50.000, on es troba situada la parada considerada. En aquesta ocasió totes les aturades es realitzaran dintre dels fulls 181 (o d’Esterri d’Àneu) i 214 (o de Sort).

També utilitzarem el full $n^{\circ} \mathbf{5 4}$ ( Vall Fosca, Montsent de Pallars i Vall de Manyanet) del Mapa Topogràfic de Catalunya, a escala 1: 25.000, publicat per l'Institut Cartogràfic de Catalunya.

Així doncs, la relació de les parades ordenades, que constitueixen aquest itinerari, és la següent. 


\subsection{Parada 1. APARCAMENT DE MAIRENA, (Llessui, terme municipal de Sort, comarca del Pallars Sobirà). (Fulls 214 i 54).}

Tot i que el recorregut de l'itinerari l'iniciarem a la població de Caregue, haurem sortit des d'aquesta població per una pista forestal que va pujant fins arribar a les immediacions del Coll de Portella, per on enllaçarà amb una pista que comunica Llessui, Espui i Espot. En trobar aquesta pista, anirem cap el Sud, fins arribar a l'aparcament de Mairena, ens caldrà deixar el cotxe, per tal de fer un nou recorregut a peu. Tot i així, en aquest indret, farem una primera aturada.

En aquest recorregut, hem continuat trobant afloraments dels materials paleozoics. Així, es fan palesos per arreu els nivells carbonats del Devonià, els qual formen part de l'Aureola de contacte. En aquest recorregut, hem anat veients diferents aspectes de la morfologia glacial $\mathrm{i}$ periglacial per tot arreu.

\subsection{Parada 2 - CONDICIONAL. INDICIS DE MANGANÉS DEL PAS DE MAIRENA, (Llessui, terme municipal de Sort, comarca del Pallars Sobirà). (Fulls 214 i 54).}

Des de la parada anterior, cal anar a peu cap el Nord, per la Vall de la Mairena, remuntant el riuet del mateix nom. Així, anirem pujant per l'esquerra del riu (en sentit descendent del mateix). Poc després d'arribar a la Cabana de la Solana del Tron (d'Altron), ens caldrà fer una nova aturada. Així, haurem efectuat un recorregut aproximat d'uns 200 - 300 metres.

En aquest recorregut, hem anat trobant els materials esmentats a les aturades anteriors. Així, ara aquí es fan paleses les calcàries del Devonià. Aquestes afloren per arreu a l'indret on ara som.

En aquest indret hi ha unes mineralitzacions estratiformes de minerals de manganès. De fet, es tracta d'unes calcaries enriquides amb òxids de manganès. Tot i això, els minerals d'aquest metall no es fan palesos, ja que es tracta d'una substitució parcial del calci dels carbonats per manganès. Així, els minerals que hi trobem són: CALCITA i indicis de MANGANOCALCITA.

Tot $\mathrm{i}$ així, no es poden extreure mostres minerals, per estar situat dintre d'un Parc Nacional, a excepció de gaudir d'una autorització del parc, per tal de fer anàlisis de les mostres, si s'escau.

\subsection{Parada 3. ESTANYS DE LA MAIRENA, ESTANY XIC DE LA MAINERA (Llessui, terme de Sort, comarca del Pallars Sobirà). (Fulls 214 i 54).}

Des de la parada anterior, cal seguir a peu, per la Vall de la Mainera, remuntant el riuet del mateix nom. Així, poc a poc anirem ascendint cap els estanys. En arribar-hi al primer, podem fer una nova aturada. Així, haurem pujat uns $\mathbf{3 0 0}$ metres de desnivell, després de recórrer a peu uns $5-6 \mathrm{Km}$, aproximadament

En aquest recorregut, haurem trobat afloraments dels materials esmentats a les aturades anteriors. Així, haurem estat circulant per l'aureola metamòrfica, molt prop del contacte amb les roques granítiques i granodiorítiques del Carbonífer. Així, haurem vist afloraments de les calcàries i pissarres del Devonià; i també de les pissarres del Silurià, de vegades en posició invertida.

En arribar a aquest indret veurem un estany, d'origen glacial; però abans d'arribar-hi haurem tingut que travessar una morrena. 


\subsection{Parada 4. ESTANYS DE LA MAIRENA, ESTANY GRAN DE LA MAINERA (Llessui, terme municipal de Sort, comarca del Pallars Sobirà). (Fulls 214 i 54).}

Des de la parada anterior, cal fer un petit recorregut, per tal d'arribar fins a l'estany Gran de Mainera i cap a una antiga pedrera de marbres situada a la seva bora. Així, des de la parada anterior, haurem efectuar un recorregut proper a $1 \mathrm{Km}$, ascendint poc més de 50 metres, per tal d’arribar fins aquí.

En aquest indret estem molt prop del contacte entre els materials de l'aureola metamòrfica (fonamentalment dels nivells de marbres del Devonià) amb les granodiorites. Fruit d'aquest contacte és l'existència d'una mineralització associada a skarn. Així es poden veure molts cristalls d’EPIDOTA.

Tanmateix es troben mineralitzacions de coure, amb la presencia de: BORNITA, CALCOPIRITA i diversos minerals d'alteració, com ATZURITA, AURICALCITA i MALAQUITA.

Tot i així, malgrat la presencia d'aquests minerals, cal considerar en tot moment que no es poden extreure mostres minerals, per estar situat dintre d'un Parc Nacional.

Per d'altra banda, en aquest indret hi ha un interessant llac d'origen glacial. Es tracta de l'estany gran de Mairena. Així, tota aquesta zona te un gran valor patrimonial; per la presencia del contacte entre les roques metamòrfiques i les roques granítiques, per la presencia de les mineralitzacions i per l'existència d'aquesta zona lacustre.

\subsection{Parada 5. ESFONDRAMENT DE LA PORTELLA, (Llessui, terme de Sort, comarca del Pallars Sobirà). (Fulls 214 i 54).}

Després de fer l'aturada anterior, cal tornar de nou a la Aparcament de Mairena, per tal de retornar cap el Coll de la Portella, fent un recorregut per la pista que va conduint cap a Espot. Així, aviat començarem a pujar cap el Coll de la Portella. Abans, però, ens caldrà fer una nova aturada a uns $2^{\prime} 5 \mathrm{Km}$ de la parada anterior.

En aquest recorregut, anirem remuntant els relleus de la Serravilla, entre afloraments dels materials paleozoics, fonamentalment del Silurià i del Devonià. Tot i així, els primers es fan molt evidents (situant-se a la part baixa), donant lloc, com a conseqüència de la seva plasticitat, a freqüents fenòmens de solifluxió, de desplaçament de vessants. Així, per arreu, en aquest tram del recorregut, es poden veure nombrosos exemples d'aquest tipus de morfologia periglacial.

Cal dir que tots aquests materials, encavalquen als esquistos de I'Ordovicià, situats més avall. L'encavalcament es produeix mitjançant la plasticitat dels materials del Silurià. Tanmateix, per sobre d'on som, hi ha un altre encavalcament, el de Serravilla, entre els materials del Devonià

En aquest indret, es pot observar un fenomen típic d'esfondrament en cullera. (fotografia 1). 


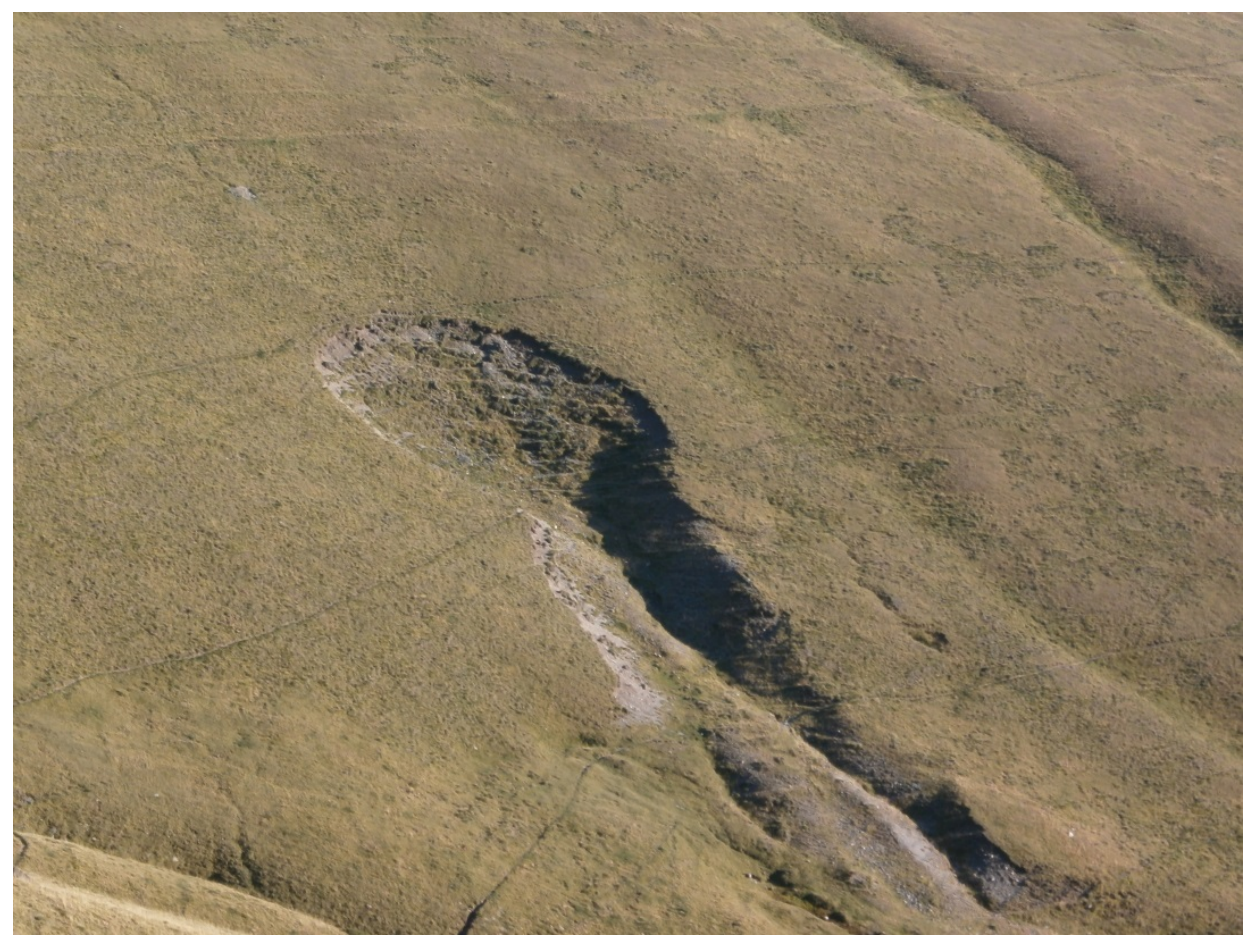

Fotografia 1. Esfondrament en cullera de la Portella. Fotografia d'Octubre del 2013

\subsection{Parada 6. COLL DE LA PORTELLA, (Caregue, terme municipal de Rialp, comarca del Pallars Sobirà). (Fulls 181 i 54)}

Des de la parada anterior, cal continuar, cap el Nord, arribant ara al Colletó de la Portella i cap el Coll de la Portella. Aquí farem una nova aturada a poc menys de 0 ' $5 \mathrm{Km}$ des de l'aturada anteriorment realitzada. Així, ara ens trobem situats per sobre de la Vall de Mairena, on hem anat abans. També estem propers a la cruillla de la pista de Caregue, per on hem arribat.

En aquest recorregut, hem anat trobant els materials del Devonià que hem esmentat al recorregut cap a l'aturada anterior, els quals es troben situats sobre els materials del Silurià. Ara hem arribat molt a prop de I'Encavalcament de Serravilla, situat per sobre nostre, a ponent.

En aquest indret, es pot fer una interessant visió, dels relleus del Pallars Sobirà i de I'Alt Urgell. Així, es ben visible la Serra del Cadí, mirant cap a llevant i cap el Sud. (fotografia 2).

Tanmateix, des d'aquest indret, mirant cap al NE es poden veure els relleus de la Pica d’Estats, del Sotllo i del Monteixo, entre altres indrets del Pallars Sobirà. (fotografia 3). 


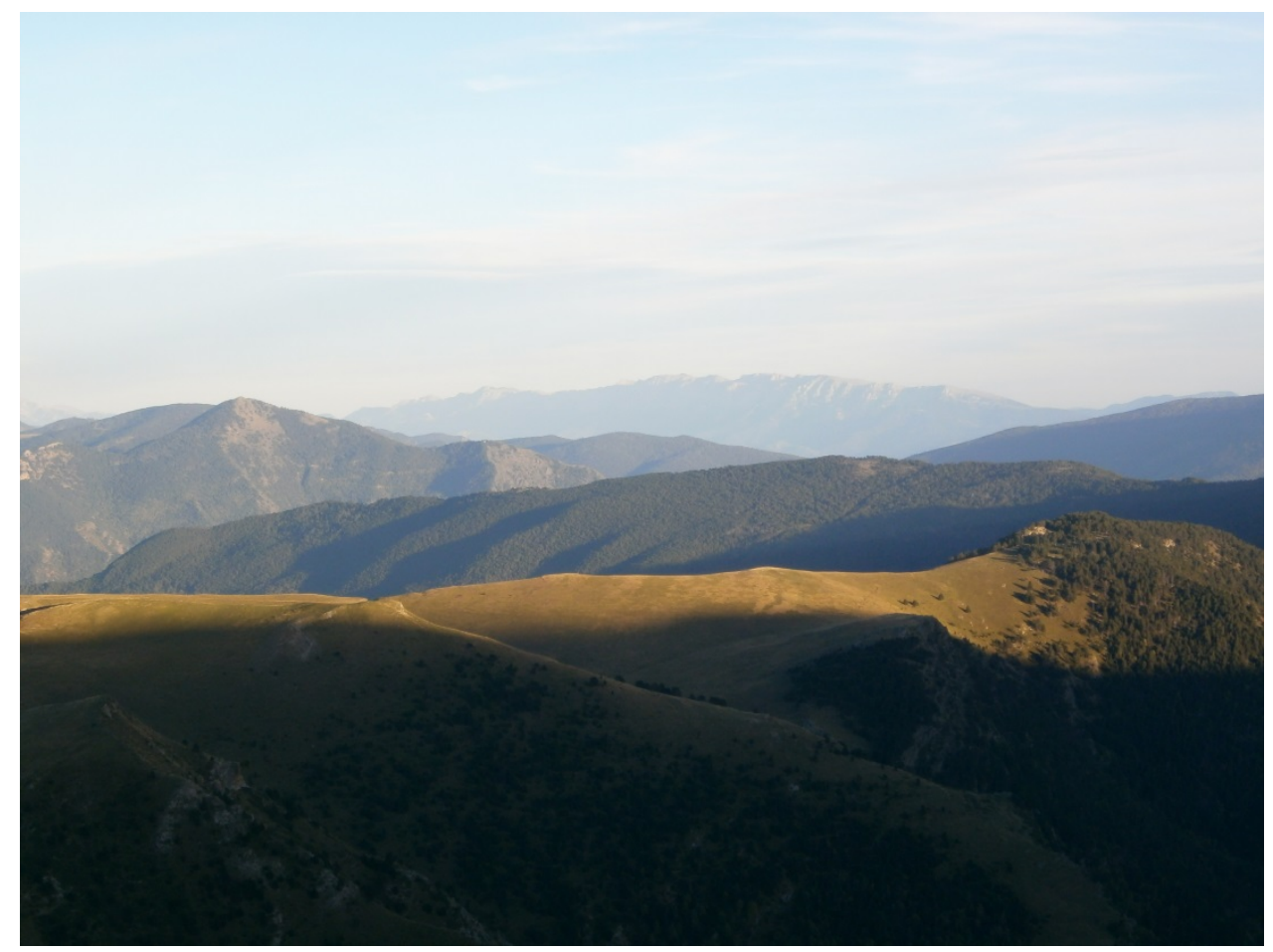

Fotografia 2. El Cadí, des del Coll de la Portella. Fotografia d’Octubre del 2013

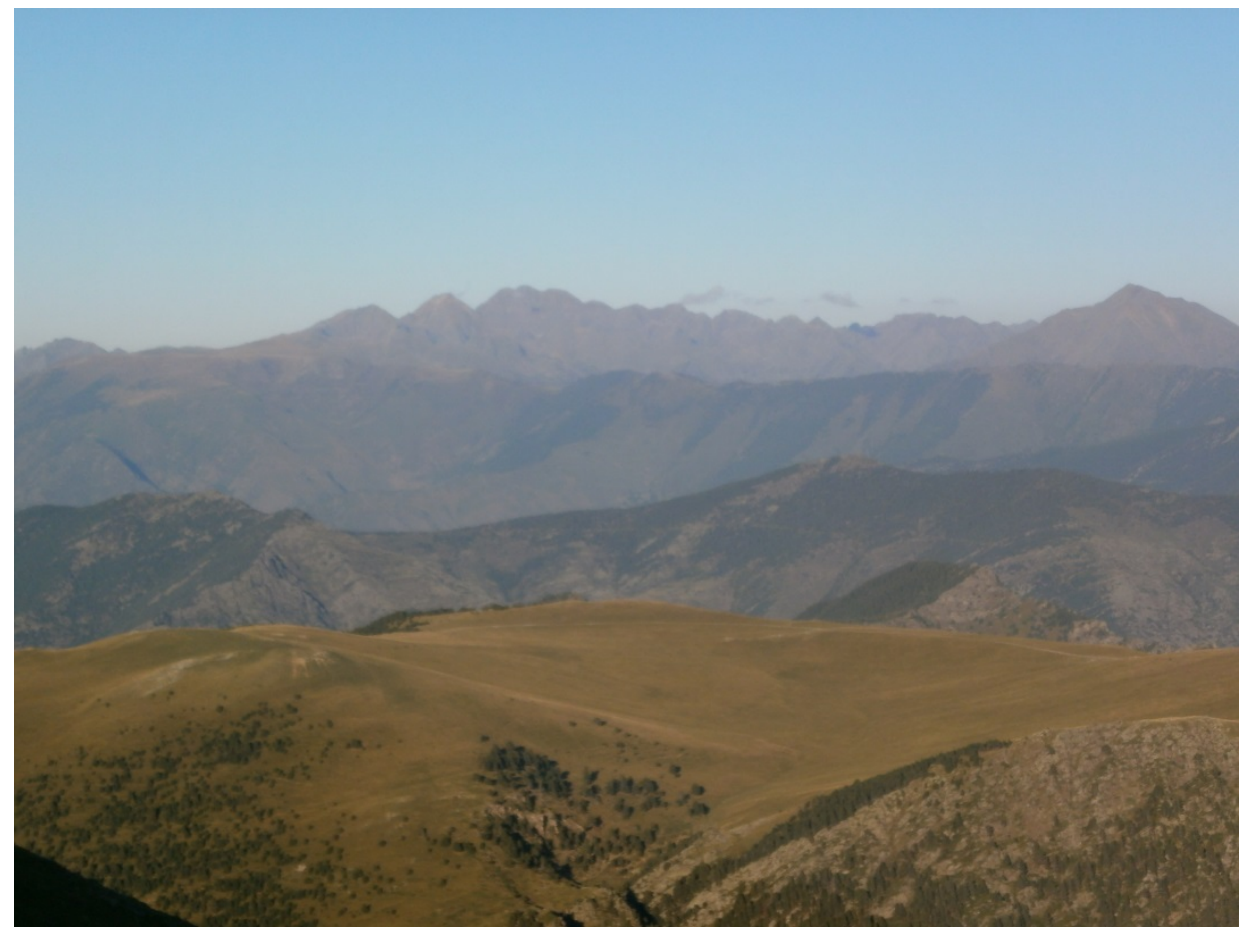

Fotografia 3. La Pica d'Estats (al centre), el Sotllo (a la dreta) i el Monteixo (a l'esquerra), des del Coll de la Portella. Fotografia de l'Octubre del 2013 Caregue alCcoll de Portella, al Estanys de Mairena, al Coll d’Eixol i a Superespot 


\subsection{Parada 7. COLLADA DE LA SERRA DELS ESTANYETS. IMMEDIACIONS DE LA FONT BLANCA, (terme municipal d'Espot, comarca del Pallars Sobirà). (Fulls 181 i 54).}

Des de la parada anterior, cal continuar, una vegada més cap el Nord, anant sempre cap a la població d’Espot. En aquest recorregut, haurem deixat per l'esquerra el camí que dirigeix cap a Caregue. Més endavant, arribarem a les immediacions de la Serra dels Estanyets. I poc després a una colladeta, per on podem fer una nova aturada, a uns $3 \mathrm{Km}$ de l'anteriorment realitzada.

En aquest recorregut, anirem trobant afloraments dels materials esmentats a les aturades anteriors, els quals pertanyen al Devonià. Així, haurem vist afloraments dels materials carbonatats. Cal dir, també, que ens continuem trobant situats dintre dels denominats Apilaments Antiformes de la Zona Axial Pirinenca. Estem situats dintre de I'Aureola de Metamorfisme.

En aquest indret, caminant des del camí cap un turó proper, podem fer una observació similar a la de la parada anterior. Així, es fan palesos en la llunyania els relleus del Cadí, de la Pica d’Estats, del Sotllo i del Monteixo, entre altres relleus. També es fa palès en primer terme el Barranc de Caregue. Cal dir que aquest neix prop d'on ara som. Concretament a la denominada Font Blanca, visible des de les proximitats d'on ara ens trobem situats. (fotografia 4).

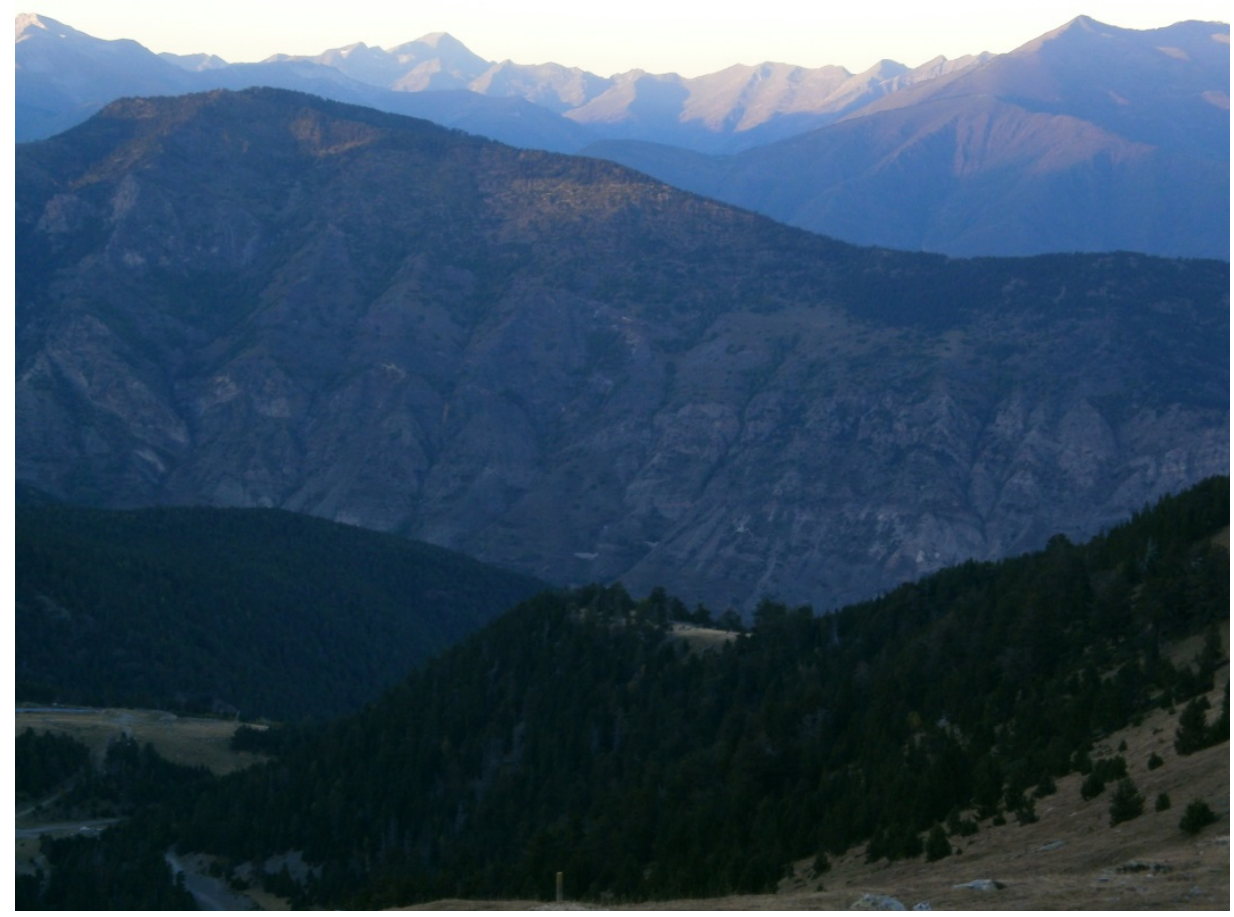

Fotografia 4. Relleus de la Pica d'Estats i del Sotllo, des de la Collada de la Serra dels Estanyets. En primer terme hi ha el Barranc de Caregue. Fotografia del capvespre d'Octubre del 2013 


\subsection{PARADA 8. COLL D'EIXOL, (terme municipal de Espot, comarca del Pallars Sobirà). (Fulls 214 i 54).}

Des de la parada anterior, cal continuar, una vegada més cap el Nord, anant sempre cap a la població d'Espot. En aquest recorregut, haurem deixat per l'esquerra el camí que dirigeix cap a Escart i cap a Baiesca. Més endavant, arribarem al Cap de la Socarrada, des d'on podem fer un petit desplaçament, per tal d'anar cap el Coll d'Eixol. Aquí, podem fer una nova aturada, a uns $2 \mathrm{Km}$ de la parada anterior, després de sobrepassar el Refugi Forestal de Quatrepins i el mateix coll.

En aquest recorregut, hem continuat trobant els materials esmentats a les aturades anteriors. És a dir: ens continuem trobant dintre de l'aureola de metamorfisme, i haurem vist els nivells de les calcàries i pissarres del Devonià. Aquests són els materials que apareixen a l'indret de I'aturada.

També, en aquest recorregut, haurem trobat bons exemples de geomorfologia glacial i periglacial, per tot arreu. Així, cal dir que des de les immediacions del coll es pot gaudir d'una bona visió (en dies clars) d'una bona part del Pallars Sobirà i del conjunt dels Pirineus, similar a la de les parades anteriors. Així es poden veure eles relleus de la Pica d'Estats i del Sotllo, entre altres indrets. També, es pot veure el relleu glacial del riu Escrita, que discorre prop d'Espot. (fotografia 5).

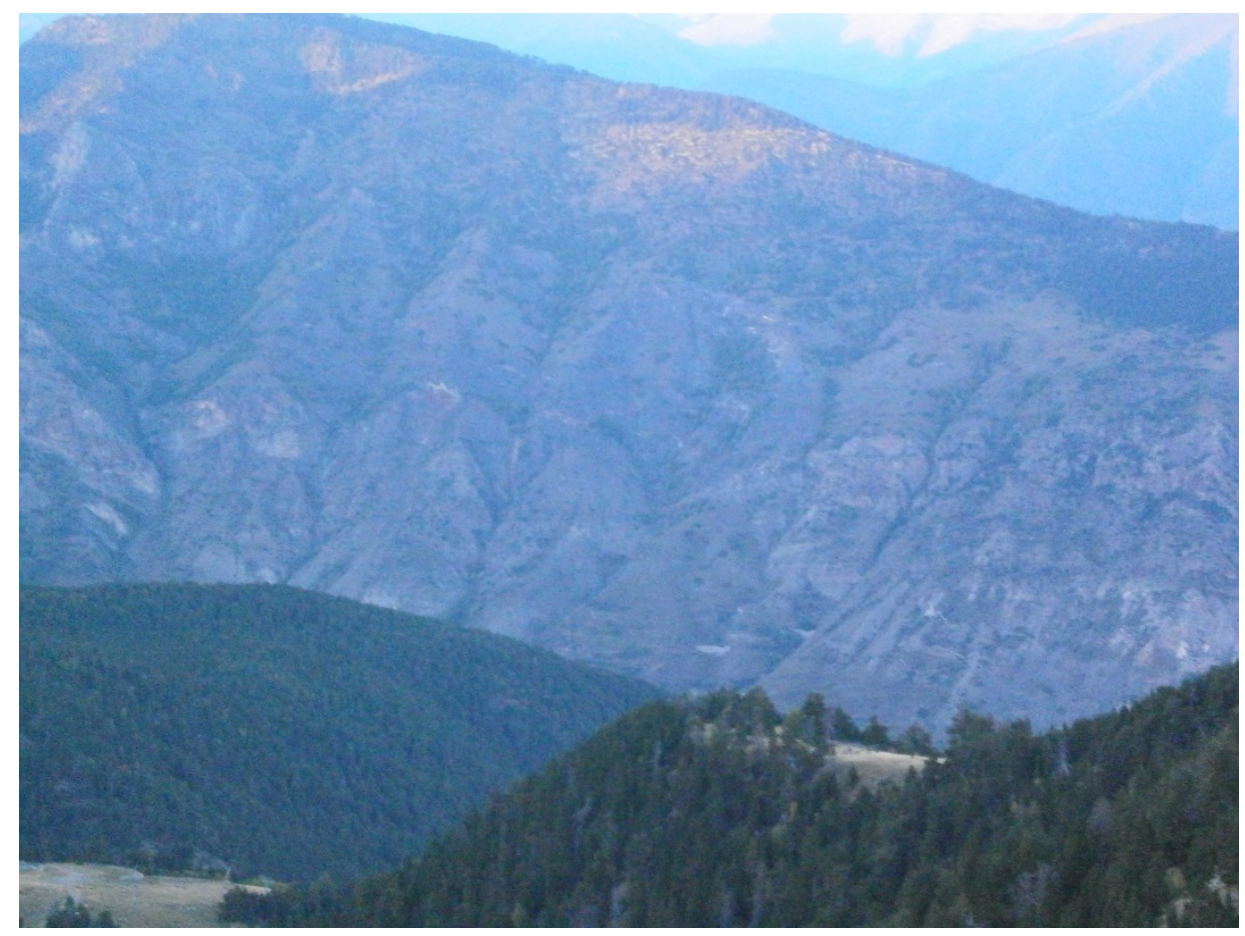

Fotografia 5. La Vall glacial del riu Escrita, des de les immediacions del Coll d’Eixol. Fotografia d'Octubre del 2013 


\subsection{PARADA 9. SUPERESPOT, IMMEDIACIONS DE LA COMA DELS ESTANYETS - NORD DE LA PICARDA, (terme municipal de Espot, comarca del Pallars Sobirà). (Fulls 214 i 54).}

Des de la parada anterior, cal continuar, una vegada més cap el Nord, anant sempre cap a la població d'Espot. En arribar prop de les instal-lacions de Superespot, ens caldrà agafar un camí que es dirigeix cap a la Bassa i cap a la Coma dels Estanyets. Per aquest indret, ens caldrà deixar el cotxe, per tal de seguir a peu cap el Sud, ascendint fins una petita coma, situada al Nord de la Picarda. En aquest indret, farem una nova aturada. Així, des de l'anterior, haurem recorregut uns $3 \mathrm{Km}$ més. I alhora, haurem fet un ascens a peu d'uns 100 metres de desnivells.

En aquest recorregut, hem continuat trobant els afloraments dels materials esmentats a les aturades anteriors. Per d'altra banda, ara ens situem a l'aureola de contacte i es fan paleses diferents skarns.

Precisament, en aquest indret es poden veure molts bons cristalls d'EPIDOTA, creixent entre la CALCITA i el QUARS, formant inclusions. També hi ha abundant TREMOLITA (en forma $d^{\prime}$ 'amiant). Sense cap mena de dubte, es tracta d'un indret important del Patrimoni Mineralògic de Catalunya. Tot i així, malgrat la presencia d'aquests minerals, cal considerar en tot moment que no es poden extreure mostres minerals, per estar situat dintre d'un Parc Nacional.

En aquest indret finalitza el recorregut de l'itinerari.

\section{Bibliografia}

GUIMERÀ, J. et altri (1992).- Geologia (II), Història Natural dels Països Catalans, Vol. 2, 547 pag. Enciclopèdia Catalana, S.A. Barcelona.

MARTíNEZ RIUS, A. Et altri (2013).- Guia Geològica del Parc Natural d'Aigüestortes i Estany de Sant Maurici. Publicada a Guies Geològiques dels Parcs Nacionals (dirigida per Roberto Rodríguez Fernández). IGME -Edit Everest. 225 pàgines. Madrid.

MATA-PERELLÓ, J.M. (1991).- Els Minerals de Catalunya. Arxius de la Secció de Ciències de I'Institut d'Estudis Catalans, vol.47, 545 pàgines. Barcelona.

MATA-PERELLÓ, J.M. (2013a).- Apunts per a un recorregut de recerca geològica $i$ mineralògica per la comarca del Pallars Sobirà: des de Llessui al Coll de Triador, a Entremonts, als Estanys de Mairena i a Espot. Inèdit. 10 pàgines. Manresa.

MATA-PERELLÓ, J.M. (2013b).- Recorregut de recerca geològica i mineralògica per la comarca del Pallars Sobirà: des del Coll de Triador, a Entremonts, al Pas de Mairena, a la Portella i al Coll d'Eixol. Inèdit. 16 pàgines. Manresa.

MATA-PERELLÓ, J.M. i SANZ BALAGUÉ, J. (1993).- Guía de identificación de Minerales, adaptada fundamentalmente a la Península Ibérica. Parcir, Edic. Selectas, 243 pàgines. Manresa.

RIBA ARDERIU, O. et altri (1976).- Geografia Física dels Països Catalans. Edit Ketres. 211 pàgines. Barcelona. 